\title{
Introduction: special issue on the economics of climate change and sustainability (Part A)
}

\author{
Elettra Agliardi, ${ }^{1 *, \dagger}$ Marco Casari, ${ }^{1 \dagger}$ and Anastasios Xepapadeas ${ }^{1,2 \dagger}$ \\ ${ }^{1}$ Department of Economics, University of Bologna, Bologna, Italy and ${ }^{2}$ Department of International and \\ European Economic Studies, Athens University of Economics and Business, Athens, Greece \\ ${ }^{*}$ Corresponding author. E-mail: elettra.agliardi@unibo.it \\ ${ }^{\dagger}$ Guest Editor
}

(Submitted 20 September 2018; revised 21 September 2019; accepted 21 September 2019)

\begin{abstract}
Climate change is one of the most significant and complex challenges facing the world's economies. The necessity to enlarge the knowledge base regarding climate change and its impacts and to design efficient policies is widely accepted by the scientific community, the decision makers and the general public. This special issue, which will be published in two parts in the current and subsequent issue of Environment and Development Economics, is a selection of papers related to the topic of the international workshop on 'The Economics of Climate Change and Sustainability' organized by the Economics Department of the University of Bologna in April 2018. The papers in this special issue cover a wide range of climate-change-related topics, which include endogenous growth and overlapping generation models; climate-related financing and green bonds; demographics; location decisions; technology diffusion; quantitative relationships and experimental approaches. We hope that this special issue will provide some new insights into the economics of climate change and help to identify new directions for future research.
\end{abstract}

Keywords: climate change; sustainability

\section{Climate change: the ultimate externality}

Climate change - brought about by human actions - is recognized nowadays as a significant and complex challenge facing the world's economies. It requires urgent actions and effective policies to avoid irreversible detrimental impacts on the natural environment and the economy worldwide. Scientific journals, reports, books, newspapers and Internet sites reflect the continuous developments and emphasize the seriousness of this issue for the world's ecosystems and population, as indicated by a few examples below.

The Intergovernmental Panel on Climate Change (IPCC), the world's most wellknown and respected authority on climate change, recently released a special report on global warming, Global Warming of $1.5^{\circ} \mathrm{C}$. With regard to the objective of limiting global warming to $1.5^{\circ} \mathrm{C}$ above pre-industrial levels, the report estimates that human 
activities have caused approximately $1.0^{\circ} \mathrm{C}$ of global warming above pre-industrial levels to date, and that global warming is likely to reach $1.5^{\circ} \mathrm{C}$ between 2030 and 2052 if it continues to increase at the current rate (IPCC, 2018). The report explains why it is vital to maintain the global temperature increase below $1.5^{\circ} \mathrm{C}$. Moreover, it indicates that there is a high degree of agreement among scientists that the impacts of $1.5^{\circ} \mathrm{C}$ of warming would disproportionately affect disadvantaged and vulnerable populations through food insecurity, higher food prices, income losses, lost livelihood opportunities, adverse health impacts and population displacements. Global warming is therefore of tantamount importance to developing as well as developed economies.

Mankoff et al. (2019) present alarming news about the acceleration in the melting of Greenland's massive ice sheet - which contains enough frozen water to raise sea levels worldwide by up to $7 \mathrm{~m}$. Thus, the melting potentially impacts all people living in low-lying areas. In addition, global warming likely affects flooding and severe storms. The website of the U.S. Environmental Protection Agency (https://www.epa.gov/arc-x/ climate-adaptation-and-storms-flooding), for example, notes that 'Climate change is projected to increase the frequency and intensity of storms in all regions of the U.S.' and that these storms can lead to 'extreme flooding and other impacts' that can overwhelm or damage water infrastructure.

At the same time, droughts - which affect everything from agriculture and water supply to transportation and health - are also linked to climate change. A new study by Marvel et al. (2019) investigated humans' influence on $20^{\text {th }}$-century drought patterns using historical weather data and drought maps calculated from tree rings. They found that a data 'fingerprint' - a drying and wetting pattern predicted to occur in response to greenhouse gas emissions - was visible as far back as the early 1900s, and is getting stronger in recent decades. The 'fingerprint' predicts that parts of Asia would become wetter in response to greenhouse gas emissions, while the southwestern United States, Central America and Europe would become drier. These results show that climate change is not just a future problem but is happening now and that the undesirable trends will continue as the world is getting warmer. Predictions indicate that droughts will become more frequent and severe as temperatures rise, potentially causing food and water shortages, human health impacts, destructive wildfires and conflicts between peoples competing for resources.

Furthermore, the chief of the Biospheric Sciences Laboratory at NASA's Goddard Space Center warned recently that climate change is making big wild fires - such as those experienced in California, the Amazon and Siberia - more likely to occur and harder to suppress (Geimann, 2019). Moreover, the effects of the record number of fires in the Amazon in 2019 could impact the whole world since the Amazon rainforest acts as a huge carbon sink, absorbing and storing carbon dioxide and helping to regulate the global climate.

\section{Climate change and the economy}

Against the backdrop of growing concern about the lack of progress in combatting climate change but, at the same time, resistance to raising environmental taxes, the German government asked the German Council of Economic Experts to compile a report discussing the options for reforming climate policy. The report, 'Setting out for a new climate policy' (German Council of Economic Experts, 2019), states that 'Any climate policy that ignores economic considerations is ultimately doomed to failure'. 
Furthermore, the Network for Greening the Financial System (NGFS, 2019), a group of Central Banks and Supervisors, recognizes that 'there is a strong risk that climaterelated financial risks are not fully reflected in asset valuations'. Moreover, NGFS members acknowledge that climate-related risks are a source of financial risk and that it is therefore within the mandates of central banks and supervisors to ensure that the financial system is resilient to these risks. This growing realization links climate change to financial markets and opens a new area for research and policy design.

All the above reports stress the global nature of the issue of climate change and its impacts, and the need for effective policies to address them. To contribute to the ongoing scientific discussion aimed at understanding the complexities of the economic impacts of climate change and the design of efficient climate policies, the Economics Department of the University of Bologna organized an international workshop in April 2018 on 'The Economics of Climate Change and Sustainability' at the Bertinoro University Residence. This event, which was the second workshop on this topic organized by the Economics Department of the University of Bologna, provided a stimulating forum for economists, both senior and junior, to present their research and to engage in a fruitful exchange of ideas.

The economics of climate change is a rapidly growing area of economics which provides new results in theory and new directions for the design of policies. Given the importance that climate change has acquired for the wellbeing of the current and future generations, climate change economics is also strongly connected to sustainability. This is because business as usual scenarios in climate change policy will definitely erode the sustainability of our economies. Thus, efficient policies that are designed to slow down climate change are unquestionably sustainability policies.

The main characteristic of climate change economics is that the economy, whether it is considered from a macro or a micro point of view, is coupled with climate. The interaction between the climate and an economy, which uses fossil fuels as an essential factor of production, generates a negative global externality and the role of economic policy is to regulate this externality. This coupling of the economy with the environment in general - and climate in particular - permeates all areas of economic science.

\section{Contents of the special issue}

The articles in this special issue provide a good example of the diverse areas of economics which are related to climate change and which can provide interesting results and meaningful policy recommendations when coupled with climate.

The papers cover a wide range of climate-change-related topics, starting from a simple macroeconomic growth model which studies policy options to climate change, and continuing on to non-convexities; overlapping generation models resulting in local and global indeterminacies, and multiple steady states; financing of climate-changerelated investments and green bonds; the impact of demographics on climate change; location decisions under climate change and technology diffusion; quantitative relationships between emissions, output and abatement; and concluding with monitoring and punishment networks in an experimental common pool resource dilemma.

More specifically, this special issue consists of a selection of nine papers related to the topic of the 'The Economics of Climate Change and Sustainability' workshop. These papers are divided into Part A and Part B: the papers in Part A appear in the present (December 2019) issue of Environment and Development Economics, while the papers in Part B appear in the February 2020 issue of the journal. 
The five contributions included in Part A of this special issue start with a paper that develops a simple model of the basic climate economic setting, which provides an illustrative intuition for different model mechanisms and the effects of different climate policies. Albeit simplified, it is sufficiently flexible so as to address important issues directly related to climate change policies that are further expanded in the subsequent contributions included in Part A. More specifically, the other four contributions dig deeper into the issue of multiple equilibria economies arising in the presence of environmental externalities and suggest meaningful policies for fostering the transition from fossil-fuel intensive technologies to low-carbon - or 'green' - economies.

The contributions in Part B of the Special Issue deal with more applied and empirical issues, such as the impact of demographic changes, the different types of climatemitigation technologies transfer between developed and developing countries, the relationship between environmental policy stringency and income growth in developed/developing countries, and an experimental study of monitoring and punishment in common pool resources.

Let's turn now to a brief description of the articles in Part A. The first paper, 'Economics of climate change: introducing the Basic Climate Economic (BCE) model', authored by Lucas Bretschger and Christos Karydas, develops a Basic Climate Economic (BCE) model. The BCE model reproduces core elements of climate change and their macroeconomic impact, incorporating fossil stock depletion, pollution externalities, capital accumulation and endogenous growth. The authors state that 'environmental economics models are often too complex to be communicated in an illustrative manner' and for this reason they provide a simple model, avoiding complex high-brow mathematics and employing graphical analysis and verbal explanations to deploy their deep reasoning in climate economics, and suggest the need for policies to regulate climate change - which could take the form of carbon taxes, decommissioning of the resource stock, or abatement.

In the second paper, 'The impact of green preferences on the relevance of history versus expectations', Andreas Schaefer and Anna Stünzi analyze the interplay between green preferences, expectations and environmental policies for the equilibrium selection process. In a model with multiple steady states, they show that for agents with green preferences, the switching to a clean production happens faster because they also hold more optimistic expectations about economic development and are willing to support higher energy taxes, which makes an early switch more attractive. On the contrary, if expectations are pessimistic, it is more likely that the economy will experience a transition to an inferior polluting equilibrium.

'Financing environmentally-sustainable projects with green bonds' by Elettra Agliardi and Rossella Agliardi - the third paper in Part A - is the first theoretical contribution to study the effects of climate-related risks on the bond market and suggests green bonds as a financial tool for facilitating the transition to a low-carbon economy. Green bonds are bonds whose proceeds are directed to projects with environmental benefits, primarily climate change mitigation and adaptation. The authors develop a structural model, providing an explicit expression for green bond values, and discuss the impact on portfolio allocations. The novel idea of the article is to consider the way in which investors' green preferences and decisions might affect the financial market outcome and thus accelerate the transition to low-carbon economies.

Larry Karp and Thierry Paul, in their paper 'Cross-sectoral pollution externalities and multiple equilibria', look at the rather complicated analytics concerning the source of multiple equilibria in dynamic models with coordination problems, such as those 
that arise in the presence of cross-sectoral pollution externalities. They study the case where the relation between the adjustment costs in mobile factors and the likelihood of multiple equilibria is non-monotonic and show the conditions such that a decrease in frictions can decrease the coordination problems, contrary to what is usually expected in standard models without this type of externalities, where coordination problems may actually increase as a result of a decrease in adjustment costs.

The fifth and last paper of the first group of contributions, 'Maladaptation and global indeterminacy' - authored by Angelo Antoci, Luca Gori, Mauro Sodini and Elisa Ticci presents a model that can generate different long-term outcomes, convergence to a stationary state following a unique trajectory, or local/global indeterminacy. In the last scenario, initial conditions (history) and individual expectations matter and the model can generate coordination failures and endogenous fluctuations. Individuals may react to environmental damages through mitigation or adaptation. However, different initial choices may imply different long-term behaviors and individual wellbeing, and coordination failures may arise along with the negative effects due to the subsequent self-feeding adoption process of maladaptive choices. The authors suggest that environmental policies promoting green production techniques and processes may help reduce coordination failures in agents' mitigation and adaptation choices.

The articles in Part B of the special issue - which will appear in the February 2020 issue of Environment and Development Economics - continue the exploration of important topics in the economics of climate change and sustainability. They are described in detail in the Introduction to Part B.

Although there has been an extensive analysis of the economics of climate change, there are still a large number of open issues in terms of both theory and applied policy. The two parts of this special issue provide some new insights into these important questions and help to identify new directions for future research.

\section{References}

Geimann S (2019) California hit with biggest wildfire of 2019 as NASA warns on climate. Bloomberg, September 14, 2019. Available at https://www.bloomberg.com/news/articles/2019-09-14/ california-sees-biggest-2019-wildfire-as-nasa-warns-on-climate.

German Council of Economic Experts (2019) Setting out for a new climate policy. Available at https:// www.sachverstaendigenrat-wirtschaft.de/en/special-report-2019.html.

IPCC (2018) Summary for policymakers. In Masson-Delmotte V, Zhai P, Pörtner H-O, Roberts D, Skea J, Shukla PR, Pirani A, Moufouma-Okia W, Péan C, Pidcock R, Connors S, Matthews JBR, Chen Y, Zhou X, Gomis MI, Lonnoy E, Maycock T, Tignor M and Waterfield T (eds), Global Warming of $1.5^{\circ} \mathrm{C}$. Geneva, Switzerland: World Meteorological Organization, pp. SPM-1-SPM-33.

Mankoff KD, Colgan W, Solgaard A, Karlsson NB, Ahlstrøm AP, Van As D, Box JE, Khan SA, Kjeldsen KK, Mouginot J and Fausto RS (2019) Greenland Ice Sheet solid ice discharge from 1986 through 2017. Earth System Science Data 11, 769-786. Available at https://doi.org/10.5194/essd-11-769-2019.

Marvel K, Cook BI, Bonfils CJW, Durack PJ, Smerdon JE and Williams AP (2019) Twentieth-century hydroclimate changes consistent with human influence. Nature 569, 59-65.

Network for Greening the Financial System (2019) A call for action: climate change as a source of financial risk. Available at https://www.banque-france.fr/sites/default/files/media/2019/04/17/ ngfs_first_comprehensive_report_-_17042019_0.pdf.

Cite this article: Agliardi E, Casari M, Xepapadeas A (2019). Introduction: special issue on the economics of climate change and sustainability (Part A). Environment and Development Economics 24, 555-559. https:// doi.org/10.1017/S1355770X19000408 